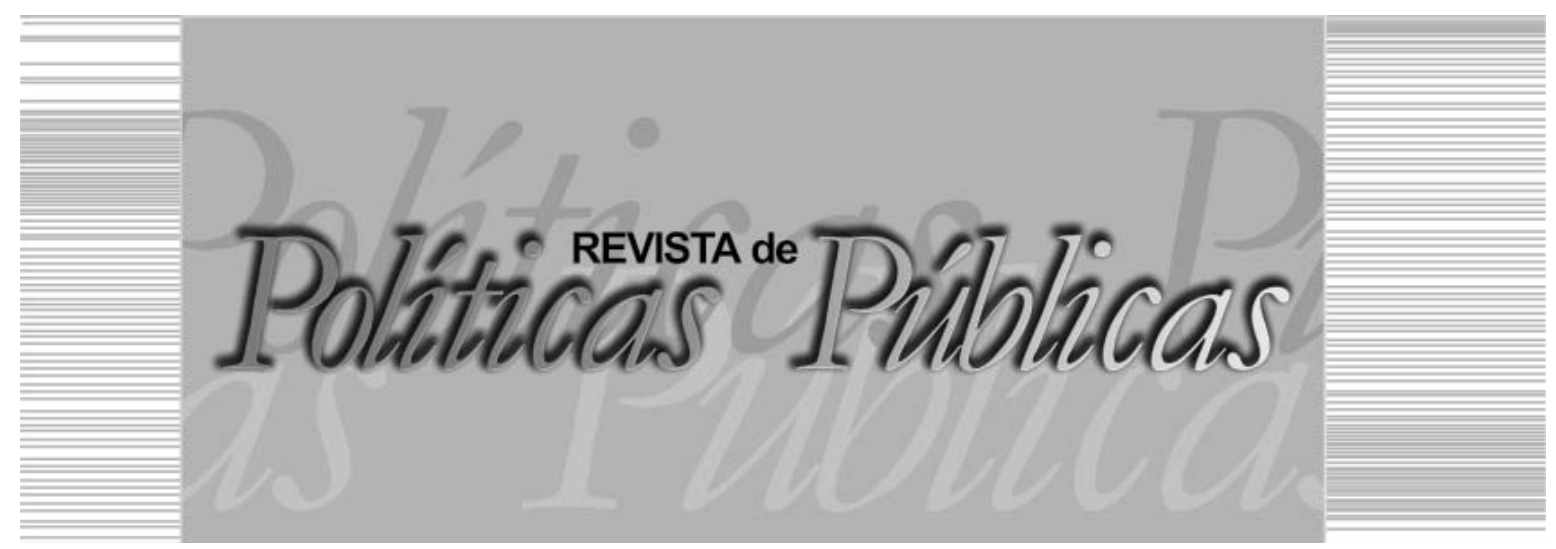

\title{
REVISITANDO A TEORIA E COMPREENDENDO A PRÁTICA: análise de casos de pagamento por serviços ambientais
}

\author{
Marcelo Silva Simões ${ }^{1}$ \\ Secretaria de Estado de Meio Ambiente e Desenvolvimento Sustentável (SEMAD)/ \\ Escola Superior de Administração, Marketing e Comunicação (ESAMC) \\ Daniel Caixeta Andrade ${ }^{2}$ \\ Universidade Federal de Uberlândia (UFU)
}

\begin{abstract}
Resumo
Reflexão sobre o debate acerca da teoria e prática das políticas de Pagamento por Serviços Ambientais (PSA). Parcela significativa da literatura aponta que a teoria convencional (abordagem coaseana) não é aderente às experiências concretas de PSA. Partindo desta constatação, o presente trabalho pretende responder duas questões: por que esta incompatibilidade entre teoria e prática acontece?; de que maneira a fundamentação teórica sobre PSA poderia ser ampliada de modo a permitir seu uso na compreensão da dinâmica concreta? As respostas oferecidas são baseadas na análise detalhada das descrições disponíveis sobre três casos internacionais e cinco casos nacionais. Os resultados obtidos corro-

1 Economista. Mestre em Economia. Gestor Ambiental da Secretaria de Estado de Meio Ambiente e Desenvolvimento Sustentável (SEMAD) e Professor Adjunto na Escola Superior de Administração, Marketing e Comunicação (ESAMC - Uberlândia). E-mail: marcelo.simoes@meioambiente.mg.gov.br/mss_1423@hotmail.com | Escola Superior de Administração, Marketing e Comunicação - ESĀMC | Praça Tubal Vilela, n. 3, $1^{\circ}$ andar, Núcleo de Inovação e Logística, Superintendência Regional de Regularização Ambiental do Triângulo Mineiro e Alto Paranaíba, Uberlândia-MG | CEP: 38400-186

2 Economista. Doutor em Desenvolvimento Econômico. Professor Adjunto do Instituto de Economia da Universidade Federal de Uberlândia (UFU). E-mail: caixetaandrade@ie.ufu. br | Universidade Federal de Uberlândia - UFU | Avenida João Naves de Avila, 2121, bloco J, sala 1J241, bairro Santa Mônica, Uberlândia-MG | CEP: 38.408-100
\end{abstract}


boram o argumento inicial e subsidiam a proposição de uma abordagem teórica mais ampla centrada nas perspectivas institucional e econômico-ecológica.

Palavras-chave: PSA, abordagem coaseana, economia institucional, economia ecológica.

\title{
REVISITING THE THEORY AND UNDERSTANDING \\ THE PRACTICE: analysis of selected cases of payment for environmental services (PES)
}

\begin{abstract}
This paper is aimed at retrieving the debate about theory and practice of Payment for Environmental Services policies. A significant portion of the literature suggests that the conventional theory that underlies the PSA (Coasean approach) does not apply for the concrete experiences of PSA. Based upon this point, this study aims to answer two questions: i) why does this mismatch between theory and practice take place in PES analysis? ii) how could the theoretical framework of PSA be expanded to allow their use in understanding the specific dynamics of PES? The answers offered draw upon detailed analyses of the descriptions available on three international and five national concrete cases of PES application. The results corroborate the initial argument, and subsidise the proposition of a broader theoretical approach focused on institutional and ecological-economic perspectives.
\end{abstract}

Key words: PSA, coasean approach, institutional economics, ecological economics.

\section{INTRODUÇÃO}

A ideia de Pagamentos por Serviços Ambientais (PSA) nasce a partir do reconhecimento da necessidade de se preservar a biodiversidade e os serviços ecossistêmicos (SEs) ${ }^{1}$. Isso porque estes últimos são considerados importantes para o bem-estar e a qualidade de vida das sociedades humanas. (ANDRADE; ROMEIRO, 2011).

A teoria de base dos esquemas de PSA é, tradicionalmente, proveniente da Economia Ambiental Neoclássica - baseada no Teorema de Coase (daí a expressão abordagem coaseana), o que contribuiu para que sua conceituação fosse feita com preocupação central na obtenção de eficiência econômica por meio da internalização de externalidades positivas via pagamentos monetários, dando valor econômico aos fluxos de SEs. A lógica, portanto, é promover comportamentos em prol de sua conservação. (WUNDER, 2005; PA- 
REVISITANDO A TEORIA E COMPREENDENDO A PRÁTICA: análise de casos

de pagamento por serviços ambientais

GIOLA; PLATAIS, 2007; ENGEL; PAGIOLA; WUNDER, 2008; FERRARO, 2008).

É possível constatar, porém, que a formalização teórica de PSA na maioria das vezes não consegue se refletir em experiências reais, expressando apenas algumas características do conceito. (MURADIAN et al., 2010). O exame da literatura especializada aponta para uma excessiva consideração dos esquemas de PSA apenas como um instrumento mercadológico, negligenciando alguns aspectos essenciais, como as complexidades ecossistêmicas e a diversidade institucional encontrada em cada contexto social.

O desacordo entre as prescrições teóricas e as condições reais pode colocar em risco a factibilidade do PSA. Isso porque realidades complexas emergem a partir das peculiaridades de cada contexto e as mesmas não podem ser analisadas a partir do marco teórico convencional. É neste contexto que se insere o problema deste trabalho, como é possível avançar de modo a tornar o marco teórico das políticas de PSA mais aderente e coerente com a complexidade dos fenômenos reais, levando em conta os contextos ecossistêmicos, econômicos e institucionais?

Por hipótese, postula-se que a teoria fundante do PSA deve ser ampliada no sentido de incorporar explicitamente objetivos de eficiência econômico-ecológica e de justiça social, entendidos como intrinsecamente interdependentes, juntamente com a trajetória histórica das instituições e as idiossincrasias dos stakeholders envolvidos. Para tanto, considera-se que as perspectivas teóricas da Economia Ecológica e Institucional (EE e EI, respectivamente) são necessárias e úteis para viabilizar tal aplicação.

O objetivo principal deste trabalho é, pois, avançar na teorização sobre PSA, incorporando de maneira conjunta elementos das visões econômico-ecológica e institucionalista, com a intenção precípua de tornar o PSA mais robusto e aplicável à realidade social, ambiental e econômica. Para tanto, foi feita uma revisão teórico-conceitual de três experiências de PSA em âmbito internacional e de cinco em âmbito nacional ${ }^{2}$.

Este trabalho é dividido em quatro partes, além desta introdução e das notas conclusivas. Primeiramente, expor-se-ão as limitações da abordagem coaseana de PSA, a partir de uma revisão da bibliográfica teórica sobre o assunto. Em seguida, será realizada 
uma análise comparativa e normativa das experiências reais de PSA abordadas. A partir desta análise, reunir-se-ão as principais contribuições e complementações dos arcabouços teóricos institucionalista e econômico-ecológico para a conceituação de PSA. Por fim, são agrupadas algumas contribuições teóricas para o aperfeiçoamento do conceito de PSA).

2 REVISITANDOATEORIA: a abordagem tradicional (coaseana) e seus limites

Do ponto de vista teórico, o PSA coaseano é visto como um instrumento que visa alcançar objetivos ambientais, especificamente conservação, restauração ou geração de SEs por meio de pagamentos diretos e condicionais àqueles agentes econômicos em condição de facto de influenciar a dinâmica de oferta dos SEs. Busca-se a resolução do trade-off entre conservação e exploração do capital natural por meio da internalização das externalidades positivas representadas pelos serviços ambientais (SAs). Caso não haja esta internalização, não há incentivos espontâneos para os SAs, já que seus benefícios são apropriados por outros agentes além daquele que o ofertou originalmente.

O mecanismo de PSA tem atraído interesse crescente por traduzir valores ambientais não mercantis e externos em reais incentivos econômicos para que os atores locais prestem SAs (ENGEL; PAGIOLA; WUNDER, 2008). A definição mais consagrada na literatura de PSA o vê como um instrumento de mercado que englobe os seguintes critérios: i) voluntariedade da transação; ii) um SA bem definido ou um tipo de uso da terra que assegure sua oferta; iii) pelo menos um comprador; iv) pelo menos um vendedor que esteja efetivamente controlando a oferta do serviço; v) se e somente se o ofertante assegurar a contínua provisão do serviço (condicionalidade) ${ }^{3}$. (WUNDER 2005; 2008; PAGIOLA; PLATAIS, 2007).

Na perspectiva coaseana, cujos princípios básicos são sistematizados no Quadro 1, o que se objetiva com a implantação de PSA é criar um incentivo econômico privado que conduza os prestadores de SAs a adotarem práticas que sejam condizentes com as demandas por SEs. Isto ocorre por meio da transferência de recursos dos compradores aos ofertantes.

A aplicação do Teorema de Coase na análise de PSA propõe que, na presença de direitos de propriedade previamente definidos 
REVISITANDO A TEORIA E COMPREENDENDO A PRATICA: análise de casos de pagamento por serviços ambientais

sobre a posse e controle do capital natural em questão e de custos de transação suficientemente baixos, haveria espaço para realização de barganhas mutuamente satisfatórias, em que contratos seriam estabelecidos redefinindo os direitos de propriedade na medida em que os beneficiários de SEs negociam com os ofertantes (de SAs), dando assim um preço ideal para a externalidade.

Quadro 1 - Síntese da conceituação coaseana de PSA

\begin{tabular}{|c|c|c|c|}
\hline $\begin{array}{l}\frac{E}{0} \\
\frac{0}{0} \\
\frac{\pi}{0} \\
\frac{8}{8}\end{array}$ & Foco de análise & $\begin{array}{l}\text { Objetivos de política } \\
\text { pública }\end{array}$ & Características principais \\
\hline 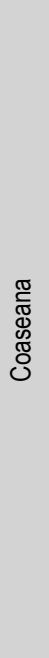 & $\begin{array}{l}\text { Oportunidades } \\
\text { de transações } \\
\text { econômicas } \\
\text { mutuamente } \\
\text { benéficas entre } \\
\text { os agentes } \\
\text { envolvidos } \\
\text { (redução do } \\
\text { problema } \\
\text { ambiental à } \\
\text { alocação eficiente } \\
\text { de recursos) }\end{array}$ & $\begin{array}{l}\text { - Escolha da opção de } \\
\text { intervenção ambiental } \\
\text { mais custo-efetiva } \\
\text { dentre as alternativas } \\
\text { disponíveis; } \\
\text { - Geração de } \\
\text { resultados Pareto- } \\
\text { eficientes (problemas } \\
\text { de alocação) via } \\
\text { internalização das } \\
\text { externalidades } \\
\text { ambientais. } \\
\text { - Utilização do mercado } \\
\text { como mecanismo capaz } \\
\text { de proceder à alocação } \\
\text { eficiente a partir do } \\
\text { momento em que os } \\
\text { problemas ambientais } \\
\text { são resolvidos. }\end{array}$ & $\begin{array}{l}\text { - Importância da definição } \\
\text { de direitos de propriedade } \\
\text { privados; } \\
\text { - Primazia dos esquemas } \\
\text { de pequena escala } \\
\text { (poucos "compradores" e } \\
\text { "vendedores" de SAs) no } \\
\text { quesito eficiência; } \\
\text { - Relação negocial estreita } \\
\text { entre "compradores" e } \\
\text { "vendedores". } \\
\text { - Centralidade da } \\
\text { voluntariedade de } \\
\text { participação e elevada } \\
\text { condicionalidade dos } \\
\text { pagamentos; } \\
\text { - Elevado grau de } \\
\text { comoditização do SEs; } \\
\text {-Alternativa mais eficiente } \\
\text { de promoção de SEs dentre } \\
\text { outras opções. }\end{array}$ \\
\hline
\end{tabular}

Fonte: Elaborado pelos autores.

Sendo um conceito baseado no funcionamento do mercado, para que um mecanismo de PSA coaseano atinja os objetivos de eficiência na utilização dos recursos financeiros é necessário elevado grau de comoditização dos SEs, elevada condicionalidade dos pagamentos e deve ser voluntário tanto na prestação dos SAs, quanto na participação no esquema. (MURADIAN, 2013; MURADIAN et al., 2013).

São raros os casos em que as experiências de PSA se adéquam a este modelo teórico. Schomers e Matzdorf (2013) buscaram 
fazer uma varredura na literatura referente às experiências de PSA, analisando 457 análises publicadas. Nesta pesquisa, os autores constataram que, de 102 experiências analisadas, apenas uma pequena minoria se adequava à conceituação coaseana (casos de pequena escala). A grande maioria das experiências se adéqua à conceituação de PSA pigouviano, ou seja, em que o governo atua como um agente do terceiro setor em benefício dos usuários de SEs, prestando uma espécie de subsídio àqueles que prestam SAs à coletividade. Portanto, funcionam em especial para bens públicos, em que não é possível evitar a presença de free-riders e que há consumo não rival dos recursos naturais.

Além dos autores acima, Muradian e outros (2010) e Simões e Andrade (2013) também exploraram o argumento de que o marco teórico do PSA não é suficiente para ancorar uma análise completa das experiências concretas de aplicação deste tipo de política. Pode-se afirmar, então, que é preciso avançar no aprimoramento conceitual de PSA de modo a conciliar teoria e prática no âmbito de análise deste tipo de instrumento. No caso específico de Simões e Andrade (2013), esses autores afirmam que é preciso delinear contribuições de outras escolas de pensamento dentro da análise econômica e social das questões ambientais (abordagem econômico-ecológica e institucionalista, principalmente).

Com o intuito de dar concretude à proposta de Simões e Andrade (2013), a próxima seção deste artigo apresenta a análise de experiências internacionais e nacionais de PSA. A partir daí, pretendeu-se compreender de que forma a EE e EI podem ser úteis para a ampliação do escopo teórico das políticas de PSA.

3 COMPREENDENDO A PRÁTICA: análise de casos selecionados de PSA em nível internacional e nacional

Para proceder à escolha de experiências de PSA internacionais e nacionais analisadas, preferiu-se aquelas cujo principal foco de implantação fosse a promoção de serviços hidrológicos ${ }^{4}$. Tal método se justifica pela necessidade de comparação entre as estratégias e os resultados de cada arranjo, e pela premência e atualidade da discussão da crise hídrica em todo o mundo. Portanto, o foco do trabalho está nos arranjos de PSA hidrológico.

Em relação às experiências internacionais, foram analisados dois casos de experiências de PSA que, a posteriori, percebeu-se que 
REVISITANDO A TEORIA E COMPREENDENDO A PRÁTICA: análise de casos

de pagamento por serviços ambientais

se adéquam bastante ao conceito coaseano, quais sejam: o caso da marca de água mineral Vittel, na França, e do sistema da bacia hidrográfica de Catskill-Delaware, no estado de Nova York (EUA). Em ambos os casos, os serviços hidrológicos de purificação da água ofertados pelos ecossistemas locais são essenciais para a oferta de água de alta qualidade para consumo humano, sendo determinantes para a viabilidade dos negócios em questão. De acordo com esta constatação, foram desenvolvidos incentivos econômicos na forma de PSA aos produtores rurais das bacias hidrográficas de influência das regiões mencionadas.

Nos casos acima, os acordos foram estabelecidos por meio de processos de negociação visando vantagens mútuas, o que de certa forma as aproxima das negociações coaseanas. Contudo, a compatibilidade entre teoria e prática nestes casos deveu-se mais às especificidades dos locais estudados e singularidades dos contratos estabelecidos. Além disso, é forçoso reconhecer que estes casos de PSA têm escala diminuta, o que favorece a redução de custos de transação.

$\mathrm{O}$ distanciamento entre teoria e prática conforme descrito na literatura revista na seção anterior (Quadro 1) ficou mais evidente ao se analisar o programa do governo costarriquenho Pagos por Servicios Ambientales (PPSA), considerado como o pioneiro e mais bem-sucedido caso de PSA em nível nacional. Entre outras coisas, o alargamento da escala de atuação do programa, a intermediação realizada pelo governo e a existência de vários objetivos que além da eficiência alocativa são atributos próprios da dinâmica do mecanismo de PSA da Costa Rica que não permitem que o mesmo seja caracterizado como um caso puro de PSA coaseano. Os Apêndices A e $\mathrm{B}$ trazem as principais características dos casos internacionais analisados ${ }^{5}$.

No que se refere às iniciativas nacionais de aplicação do instrumento foram analisados, de iniciativa pública, o Projeto Conservador das Águas de Extrema-MG, que está inserido dentro do Programa Produtor de Águas, da Agência Nacional de Águas (ANA), e de iniciativa privada, o Programa Oásis, em São Paulo-SP e Apucarana-PR. Partindo para análise de políticas ambientais estaduais, analisou-se o programa ProdutorES de Águas, que posteriormente se transformou no Programa Reflorestar (ES), iniciativa inovadora em termos de política estadual, e que tem demonstrado avanços no sentido de ter uma abordagem integrada, com objetivos ambientais, 
sociais e econômicos. Os Apêndices $\mathrm{C}$ e $\mathrm{D}$ sintetizam as principais características de cada uma dessas experiências.

Todos os casos aqui analisados são recentes, instituídos já na segunda metade da década de 2000. O Projeto Conservador das Águas, de Extrema-MG, é a experiência mais conhecida em âmbito nacional, sendo de iniciativa do poder público municipal e englobando amplo espectro de stakeholders. Pode-se dizer que é o mecanismo mais maduro e estudado dentre os demais analisados em âmbito nacional, sendo, pois, utilizado como benchmark pelas outras experiências.

Por sua vez, o Projeto Oásis da Fundação Grupo Boticário é uma iniciativa de uma instituição filantrópica ligada a um grupo privado de capital nacional, que desenvolveu metodologia inovadora e flexível, capaz de ser adaptada às idiossincrasias das diversas regionalidades brasileiras. Iniciou suas operações na Região Metropolitana de São Paulo e posteriormente foi replicada em um mecanismo de iniciativa municipal em Apucarana-PR.

O ProdutorES de Água iniciou a implantação da política estadual de PSA, remunerando o serviço hidrológico prestado pelos produtores rurais que mantêm áreas de suas propriedades com cobertura florestal nativa em áreas de mananciais priorizadas. O Programa Reflorestar demonstra a maturidade da proposta de PSA capixaba, pois é um avanço da política no sentido de aliar estratégias de políticas agrícola e ambiental, aliando sustentabilidade ambiental, com geração de oportunidades para melhorar as condições socioeconômicas dos produtores rurais.

Os casos internacionais abordados neste trabalho são os mais antigos dentre os aqui estudados, tendo início nos anos 1990. Por isso, e pelas inovações que trouxeram, estão entre os mais estudados e discutidos na literatura especializada. Já os casos brasileiros, por serem mais recentes, ainda são carentes de estudos, demonstrando os resultados ambientais, sociais e econômicos produzidos. Há predominância da iniciativa pública para implantação dos esquemas de PSA, sendo um dos principais motivos, para tanto, o fato de que os problemas ambientais, em geral, impactam um conjunto variado de agentes. Estes consideram tais impactos como externalidades negativas que influem na prestação de serviços públicos (como abastecimento urbano de água). Portanto, há uma natural dificuldade de comoditizar os serviços hidrológicos, o que diminui a proximidade 
REVISITANDO A TEORIA E COMPREENDENDO A PRÁTICA: análise de casos

de pagamento por serviços ambientais

do PSA em relação a uma visão mais mercadológica de instrumento de política ambiental, base sobre a qual é construído o conceito de PSA coaseano.

A escala espacial se dá em bacias hidrográficas prioritárias (com exceção do PPSA, que se dá em âmbito nacional), na busca de obter maior eficiência na remuneração dos SAs prestados e, portanto, gerar maior adicionalidade ambiental. É importante salientar, também, que os esquemas financiados pelos usuários são mais focalizados comparativamente aos governamentais. As experiências brasileiras apresentam constante crescimento em sua escala, sendo em geral ainda pouco abrangentes (devido, entre outros fatores, ao pouco tempo de implantação e à escassez de recursos). No caso do Oásis São Paulo, não tem havido crescimento a partir de 2010 pela falta de recursos financeiros para contratação de novas áreas. Já o Reflorestar foi criado em substituição ao ProdutorES de Água com o objetivo de alcançar maior escala em menor período de tempo.

Nos casos governamentais, destaca-se o importante papel dos intermediários na diminuição dos custos de transação dos programas. No caso do Conservador das Águas, por exemplo, uma ampla gama de atores parceiros opera como intermediários, desde o mapeamento, instalação de cercas, apoio técnico, etc., aumentando a eficácia e a eficiência no gasto dos recursos públicos (focalizados nas atividades que produzem maiores resultados em termos de SEs). Tais características distanciam as experiências do conceito coaseano de PSA, visto que este defende que tais mecanismos sejam implantados onde os custos de transação sejam os menores possíveis. Com o apoio de parceiros e constituição de arranjo institucional sofisticado, a partir de uma visão alternativa de PSA, demonstra-se que é possível a existência de oportunidades de criação deste tipo de política, mesmo na presença de elevados custos de transação.

Como esforço de síntese da discussão apresentada neste item e tomando como base os argumentos de Simões e Andrade (2013), o Apêndice E busca relacionar as experiências de PSA analisadas neste trabalho com o grau de aderência à conceituação coaseana. Neste quadro, cuja construção foi feita a partir das informações dos estudos revisados e sua comparação com o Quadro 1 (seção 1), pode-se encontrar um grau de aderência, que varia entre baixo e elevado, além dos motivos que levam ao maior ou menor distanciamento das experiências desta modelagem mainstream. 
Percebe-se que existem diferentes motivos pelos quais as experiências de aplicação de PSA apresentadas se distanciam da conceituação tradicional de PSA. Este exercício empírico suporta a premissa básica deste trabalho e demonstra que há um distanciamento entre a teoria do PSA e sua aplicação prática. Isso sugere, pois, que esforços de pesquisa sejam direcionados para a redução deste gap. A próxima seção objetiva avançar nesta direção ao apresentar uma abordagem ampla que incorpore, de maneira conjunta, as contribuições das abordagens da EE e EI.

4 UMA ABORDAGEM MAIS AMPLA DE PSA: contribuição das perspectivas institucional e econômico-ecológica

Muradian e outros (2013) afirmam que há um risco crescente de se considerar os mecanismos de PSA como panaceias e soluções duplamente ganhadoras (win-win solutions). Isso porque é cada vez mais comum a interpretação simplista de que o PSA é uma política eficaz para a resolução do trade-off existente entre conservação ambiental e produção econômica. Contudo, a incorporação de aspectos oriundos das abordagens institucional e econômico-ecológica tornaria a análise menos simplificada, contribuindo para que o arcabouço teórico seja mais aderente à realidade.

As críticas institucionalistas e as contribuições da EE mostram complementaridades em várias questões. Exemplos estão na ênfase dos efeitos de PSA sobre a equidade, as interdependências que surgem, dadas as características de bem público dos SEs, as incertezas derivadas da escassa compreensão sobre as relações entre os diferentes usos de terra e a oferta de serviços (derivando, daí, a necessidade de uma abordagem precaucional), a importância de considerar os diferentes contextos sociais e ecológicos para adequação de um mecanismo, etc.

Baseado em toda a argumentação até então desenvolvida, o Quadro 2, abaixo, sintetiza as principais contribuições das abordagens institucionalista e econômico-ecológica para o debate sobre o desenho, implementação e monitoramento dos instrumentos de PSA. A partir de uma visão aditiva, a junção de tais contribuições aos aspectos já praticados no âmbito da abordagem coaseana faz surgir uma concepção mais ampla que pode ser chamada de abordagem econômico-ecológica e institucional de PSA, cuja principal caracte- 
REVISITANDO A TEORIA E COMPREENDENDO A PRÁTICA: análise de casos de pagamento por serviços ambientais

rística é a interpretação de que o instrumento de PSA faz parte de um contexto político-institucional específico (Figura 2).

Além disso, essa visão de PSA privilegia a interpretação de que este instrumento faz parte de um arranjo dinâmico de políticas econômicas, sociais e ambientais (policymix). Tais arranjos, por sua vez, podem apresentar coevolução, uma vez que os objetivos, metas e meios para o alcance do desenvolvimento rural sustentável devem ser socialmente acordados.

Quadro 2 - Síntese das principais contribuições das abordagem institucionalista e econômico-ecológica para a conceituação de PSA

\begin{tabular}{|c|c|c|c|}
\hline Abordagem & Foco de análise & $\begin{array}{c}\text { Objetivos de } \\
\text { política pública }\end{array}$ & Características principais \\
\hline 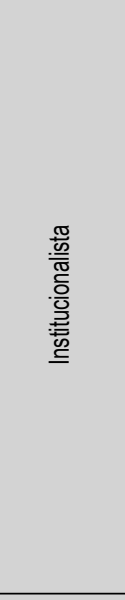 & $\begin{array}{l}\text { - Instituições contextuais; } \\
\text { - Impactos dos critérios de } \\
\text { justiça distributiva sobre } \\
\text { eficiência e equidade; } \\
\text { - Respeito à diversidade } \\
\text { de valores entre os } \\
\text { stakeholders; } \\
\text { - Importância do path } \\
\text { dependency e do } \\
\text { learning-by-doing; } \\
\text { - Destaque para o } \\
\text { papel da especificidade } \\
\text { dos ativos naturais, } \\
\text { da incerteza, ações } \\
\text { oportunistas e da } \\
\text { influência dos custos de } \\
\text { transação. }\end{array}$ & $\begin{array}{l}\text { - Construção de } \\
\text { mecanismos que } \\
\text { se adaptem às } \\
\text { especificidades } \\
\text { locais e produzam } \\
\text { resultados } \\
\text { condizentes com } \\
\text { os valores sociais } \\
\text { (problemas de } \\
\text { distribuição); } \\
\text { - Promoção } \\
\text { de efeitos } \\
\text { de equidade } \\
\text { e respeito à } \\
\text { distribuição justa } \\
\text { do poder de } \\
\text { barganha entre os } \\
\text { stakeholders. }\end{array}$ & $\begin{array}{l}\text { - Importância dos valores sociais, } \\
\text { da capacitação e da percepção } \\
\text { dos agentes e não neutralidade } \\
\text { da dotação dos direitos de } \\
\text { propriedade; } \\
\text { - Busca do desenvolvimento } \\
\text { de instituições adaptativas e } \\
\text { evolutivas, que são geradas } \\
\text { pelo arranjo de forças entre os } \\
\text { stakeholders; } \\
\text { - Centralidade do papel dos } \\
\text { intermediários para diminuição } \\
\text { dos custos de transação e para } \\
\text { equilibrar o poder de barganha; } \\
\text { - Importância da consideração } \\
\text { dos atributos das transações para } \\
\text { determinação da estrutura de } \\
\text { governança vigente e do tipo de } \\
\text { transferência monetária. }\end{array}$ \\
\hline 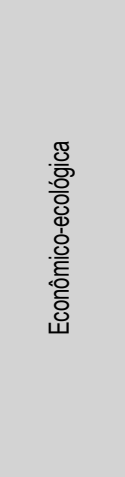 & $\begin{array}{l}\text { - Especificidade do capital } \\
\text { natural e limites biofísicos } \\
\text { para coevolução do } \\
\text { sistema socioeconômico } \\
\text { e ecológico; } \\
\text { - Conceitos de escala e } \\
\text { resiliência ecossistêmica } \\
\text { para delimitação das } \\
\text { áreas prioritárias de ação. }\end{array}$ & $\begin{array}{l}\text { - Delimitação } \\
\text { de padrões } \\
\text { biofísicos para a } \\
\text { sustentabilidade } \\
\text { do capital natural; } \\
\text { - Consideração } \\
\text { dos feedbacks } \\
\text { dos impactos das } \\
\text { ações antrópicas } \\
\text { sobre as funções } \\
\text { ecossistêmicas } \\
\text { e vice-versa, } \\
\text { num horizonte } \\
\text { de longuíssimo } \\
\text { prazo. }\end{array}$ & $\begin{array}{l}\text { - Visão sistêmica da relação } \\
\text { economia-meio ambiente } \\
\text { (natureza interdisciplinar); } \\
\text { - Princípio da Precaução - } \\
\text { incerteza quanto às relações entre } \\
\text { uso do solo e oferta de SAs; } \\
\text { - Centralidade das ideias de } \\
\text { escala econômica, resiliência } \\
\text { ecossistêmica e insubstituibilidade } \\
\text { do capital natural; } \\
\text { - Complementaridade dos capitais } \\
\text { natural e produzido pelo homem, } \\
\text { e estratégia de conciliação de } \\
\text { ambos para geração de renda no } \\
\text { campo. }\end{array}$ \\
\hline
\end{tabular}

Fonte: Elaborado pelos autores, com base na pesquisa. 
Essa nova visão mais ampla e integradora de PSA é compatível com a análise de Muradian e outros (2010). Estes autores propõem que o mecanismo de PSA, pelo menos nos países em desenvolvimento, seja considerado explicitamente como parte de um portfólio de programas e projetos de desenvolvimento rural ao invés de serem caracterizados como ferramenta econômica usada apenas para garantir proteção ambiental da forma mais eficiente possível. Nesse sentido, é necessário atenção especial ao potencial de inclusão social nestes programas, constituindo-o como um instrumento de política multiobjetivado, que busque resolver, simultaneamente, problemas de ordem ambiental, social e econômica.

Essa ideia vai ao encontro da constituição de um mix de instrumentos de política ambiental, em que o PSA interage com outros mecanismos, como transferências fiscais verdes, constituição de uma rede de unidades de conservação (formando corredores ecológicos), sistemas de certificação de produtos de sistemas agroambientais, etc. Portanto, o PSA, sozinho, não pode ser considerado como panaceia para resolução dos problemas ambientais, mas sim como uma ferramenta que quando complementada por outras, pode induzir a um estilo de produção agropecuária dentro de uma estratégia de desenvolvimento rural sustentável. (RING; SCHRÖTER-SCHLAACK, 2011; BARTON; BLUMENTRATH; RUSCH, 2013). Essa complementaridade é especialmente importante porque vai além da dicotomia usual entre instrumentos de mercado e instrumentos de comando e controle. 
REVISITANDO A TEORIA E COMPREENDENDO A PRÁTICA: análise de casos de pagamento por serviços ambientais

Figura 2 - Síntese das principais contribuições das abordagens institucionalista e econômico-ecológica para o debate sobre o desenho, implementação e monitoramento dos instrumentos de PSA

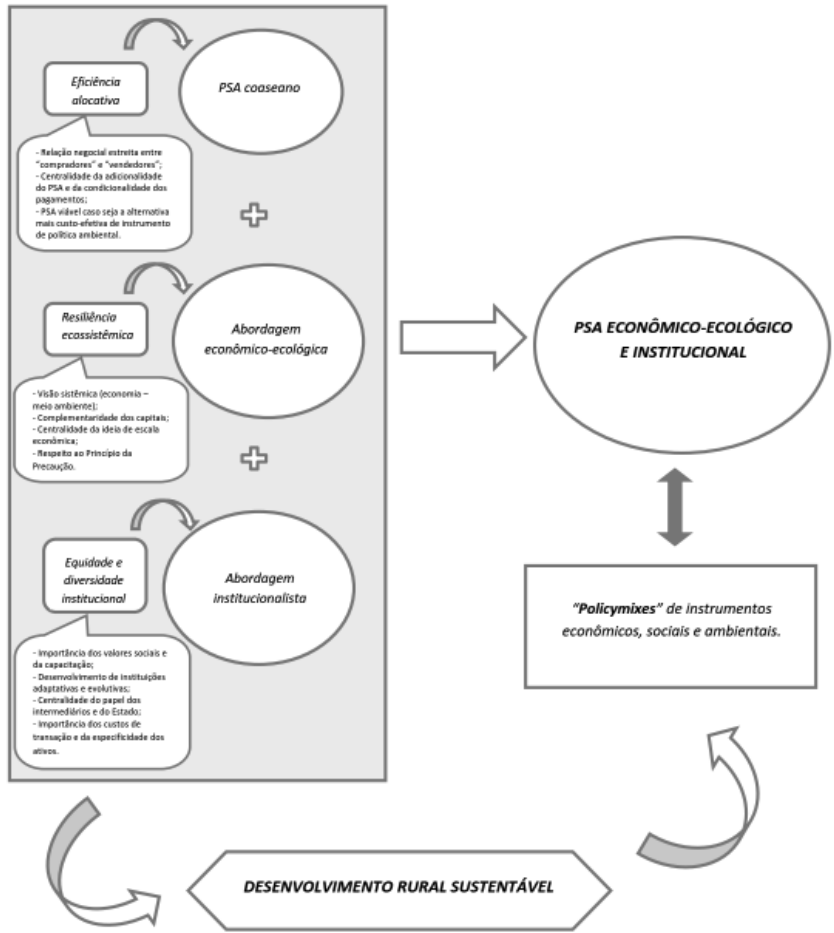

Fonte: Elaborado pelos autores, com base na pesquisa.

O ponto de partida é o reconhecimento de que os SEs são a interface básica entre capital natural e bem-estar humano (ANDRADE, 2015). Nesse caso, segundo Shiki e Shiki (2011, p.115), os pagamentos seriam considerados "[...] investimentos em infraestrutura ecológica." O objetivo principal de um esquema de PSA deve ser a criação de incentivos para a oferta de SAs, promovendo, deste modo, comportamentos individuais e coletivos que de outra forma levariam à deterioração excessiva de ecossistemas e recursos naturais. (VATN, 2010; MURADIAN, 2013).

Esta abordagem mais ampla de PSA é compatível também com uma gama maior de experiências, cuja classificação pode se dar 
em função de três critérios principais: a importância do incentivo econômico (o papel do pagamento na condução aos usos determinados da terra em relação a outros incentivos, como motivações éticas e culturais), a frequência de pagamentos diretos (a medida em que os ofertantes recebem pagamentos diretos dos beneficiários finais dos SAs) e o grau de comoditização dos SAs e SEs (a medida e clareza com a qual os pagamentos recebidos pelos ofertantes foram definidos como mercadoria comercializável). (MURADIAN et al., 2010).

Sob esta nova perspectiva, todos os programas deverão assegurar: (i) que os intermediários ajam com total prudência; (ii) que os contratos definam os direitos e responsabilidades dos atores; e (iii) que as relações de poder sejam equilibradas. A inclusão de um organismo multisetorial que reúna atores de PSA para análise e intermediação de conflitos de interesse na negociação e no desenvolvimento do esquema é desejável, pois, somado às avaliações de entidades independentes, promove o fortalecimento dos processos de adaptação e de aprendizagem contínua, o aperfeiçoamento institucional e das rotinas de governança. (OSTROM, 1990; CORBERA; SOBERANIS; BROWN, 2009).

Para o sucesso desta estratégia de política, é fundamental que seja desenvolvida uma estrutura de financiamento perene, na qual usuários de SAs compensem os ofertantes com flexibilidade por um longo período de tempo e no qual apoio contínuo para gestão sustentável de recursos é oferecida. (CORBERA; SOBERANIS; BROWN, 2009). Os atores envolvidos terão condições de tomar suas decisões com maior segurança, dado o satisfatório horizonte temporal para o planejamento de suas respectivas atividades. Aumenta-se, portanto, a credibilidade dos stakeholders quanto ao funcionamento bem sucedido destes mecanismos.

Por fim, é importante ressaltar que os argumentos desta seção são convergente com os de Van Hecken, Bastiaensen e Windey $(2015$, p. 5), para os quais "[...] PES research remains weakly theorized in social and political terms, resulting in only superficial understanding of the role of culture, agency, social diversity and power relations in the shaping of PES institutions and their outcomes." Estes autores também se utilizam do argumento de que as críticas provenientes da EE e EI são necessárias para se ampliar o modo de se pensar sobre o PSA. Ainda segundo eles, estas duas abordagens enfatizam que o PSA não é necessariamente uma mudança de 
REVISITANDO A TEORIA E COMPREENDENDO A PRÁTICA: análise de casos

de pagamento por serviços ambientais

políticas públicas para políticas de alocação via mercado. Mais do que isso, uma abordagem econômico-ecológica e institucionalista de PSA lida com a reconfiguração de relacionamentos entre estado, comunidade e mercado. Para complementar, argumenta-se que esta visão mais ampla sobre PSA também contempla a natureza dentro deste conjunto de relações, já que o conceito de SEs explicita a dependência do bem-estar humano em relação aos ecossistemas. (COSTANZA, 2011).

\section{CONCLUSÃO}

Este trabalho partiu do argumento, já existente na literatura, de que o enfoque exclusivo da abordagem coaseana de PSA sobre eficiência alocativa reduz sobremaneira sua aderência à prática corrente deste tipo de política. A partir disso, procurou-se confirmar este argumento por meio de análise de casos selecionados de PSA. Foram estudados no total 8 casos de aplicação concreta de PSA, o que foi suficiente para corroborar a tese de que há um distanciamento entre teoria e prática no que tange ao PSA.

Os resultados da revisão mostrou que apenas um estudo de caso - dentre os 8 analisados - apresenta aderência elevada à abordagem coaseana de PSA. A partir do levantamento das possíveis razões que explicam o gap existente entre o marco teórico e experiências reais, este trabalho buscou identificar as principais contribuições que a EE e EI podem prestar à reaproximação entre teoria e prática. De modo geral, foi possível concluir que estas duas perspectivas são úteis e devem ser utilizadas para a teorização das políticas de PSA. Isso porque o PSA não deve focar apenas na eficiência alocativa, mas também na sustentabilidade ambiental dos ecossistemas, entendida principalmente como respeito à resiliência ecossistêmica, e em critérios de justiça distributiva. Além disso, a implementação concreta de políticas de PSA não deve prescindir da visão de instituições como organizações evolutivas, adaptativas e reflexivas das peculiaridades e idiossincrasias locacionais.

O debate sobre a necessidade de uma nova definição de PSAé recente na literatura. (VAN HECKEN; BASTIAENSEN; WINDEY, 2015; WUNDER, 2015). O objetivo deste trabalho não foi o propor uma nova definição de PSA, mas oferecer um conjunto mais amplo de ideias e argumentos que devem ser levados em consideração neste debate. Esta abordagem mais ampla é especialmente necessária 
para experiências de PSA em países ainda em desenvolvimento, uma vez que o objetivo de sustentabilidade ambiental não deve estar dissociado do objetivo de sustentabilidade (ou equidade) social. Isto é, nestes locais específicos, a eficiência alocativa deve estar condicionada a objetivos maiores, como o da preservação do capital natural e a promoção da justiça intra e intergeracional.

\section{REFERÊNCIAS}

ANDRADE, D. C. Elementos facilitadores do entendimento das interfaces entre sistemas naturais e socioeconômicos. Holos, Natal, ano 31, v. 2, p. 155-168, 2015.

; FASIABEN, M. C. R. A utilização dos instrumentos de política ambiental para a preservação do meio ambiente: o caso dos Pagamentos por Serviços Ecossistêmicos (PSE). Economia Ensaios, Uberlândia, v. 24, n. 1, p. 113-133, 2009.

; ROMEIRO, A. R. Degradação ambiental e teoria econômica: algumas reflexões sobre uma 'economia dos ecossistemas'. EconomiA, Brasília, DF, v. 12, n. 1, p. 3-26, jan./abr. 2011.

BARTON, D. N.; BLUMENTRATH, S.; RUSCH, G. Policyscape - A Spatially Explicit Evaluation of Voluntary Conservation in a Policy Mix for Biodiversity Conservation in Norway. Society and Natural Resources, [S. 1.], v. 26, n. 10, p. 1185-1201, 2013.

CORBERA, E., SOBERANIS, C.G., BROWN, K. Institutional dimensions of Payments for Ecosystem Services: An analysis of Mexico's carbon forestry programme. Ecological Economics, [S. 1.], v. 68, p. 743-761, 2009.

COSTANZA, R. Changing the way we view humanity and the rest of nature. Solutions, [S. 1.], v. 2, n. 6, p. 1, nov. 2011.

ENGEL, S., PAGIOLA S., WUNDER, S. Designing payments for environmental services in theory and practice: an overview of the issues. Ecological Economics, [S. 1.], v. 65, p. 668-674, 2008.

FERRARO, P.J. Asymmetric Information and Contract Design for Payments for Environmental Services. Ecological Economics, [S. 1.], v. 65, p. 810-821, 2008.

MURADIAN, R. Payments for ecosystem services as incentives for Collective Action. Society and Natural Resources, [S. 1.], v. 26, n. 10, p. 1155-1169, 2013. 
REVISITANDO A TEORIA E COMPREENDENDO A PRÁTICA: análise de casos de pagamento por serviços ambientais

et al. Payments for ecosystem services and the fatal attraction of win-win solutions. Conservation Letters, [S. 1.], v. 6, n. 4, p. 274279, 2013.

et al. Reconciling theory and practice: an alternative conceptual framework for understanding payments for environmental services. Ecological Economics, [S. 1.], v. 69, n. 6, p. 1202-1208, 2010.

OSTROM, E. Governing the commons: the evolution of Institutions for Collective Action. New York: Cambridge University Press, 1990.

PAGIOLA, S.; PLATAIS, G. Payment for Environmental Services: from theory to practice. Washington D.C.: World Bank, 2007.

RING, I.; SCHRÖTER-SCHLAACK, C. Justifying and assessing policy mixes for biodiversity and ecosystem governance. In: (Eds.). Instrument Mixes for Biodiversity Policies. 2011. p. 14-35. (POLICYMIX Report, n. 2).

SCHOMERS, S.; MATZDORF, B. Payments for ecosystem services: a review and comparison of developing and industrialized countries. Ecosystem Services, [S. 1.], 2013. In press.

SHIKI, S.; SHIKI, S. F. N. Os Desafios de uma Política Nacional de Pagametnos por Serviços Ambientais: lições a partir do caso do Proambiente. Sustentabilidade em Debate, Brasília, DF, v. 2, n. 1, p. 99-118, 2011

SIMÕES, M. S. Pagamentos por serviços ambientais sob uma ótica econômico-ecológica e institucionalista: reconciliando teoria e prática. 2014. 235 f. Dissertação (Mestrado em Economia) - Programa de Pós-Graduação em Economia, Universidade Federal de Uberlândia, Uberlândia, 2014.

; ANDRADE, D. C. Limitações da abordagem coaseana à definição do instrumento de Pagamento por Serviços Ambientais (PSA). Sustentabilidade em Debate, Brasília, DF, v. 4, n. 1, p. 59-78, 2013.

VAN HECKEN, G.; BASTIAENSEN, J.; WINDEY, C. The frontiers of the debate on Payment for Ecosystem Services: a proposal for innovative future research. IOB - Discussion Paper, Belgium, n. 5, 2015.

VATN, A. An institutional analysis of payments for environmental services. Ecological Economics, [S. 1.], v. 69, n. 6, p. 1245-1252, 2010 . 
VEIGA, F., GAVALDÃO, M. Iniciativas de PSA de conservação dos recursos hídricos na Mata Atlântica. In: GUEDES, F. B.; SEEHUSEN, S. E. Pagamentos por serviços ambientais na Mata Atlântica: lições aprendidas e desafios. Brasília, DF: MMA, 2011.

WUNDER, S. Necessary conditions for ecosystem service payments. Economics and Conservation in the Tropics: a strategic dialogue, Washington, DC, p. 1-10, jan./feb. 2008.

. Payments for environmental services: some nuts and bolts.

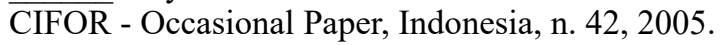

. Revisiting the concept of payments for environmental services. Ecological Economics, [S. 1.], v. 117, p. 234-243, 2015.

\section{NOTAS:}

1 Neste trabalho adotou-se uma distinção clara entre serviços ecossistêmicos (SEs) e serviços ambientais (SAs). Estes últimos se referem a uma atividade tipicamente antrópica que em última instância afetará positivamente os benefícios tangíveis e intangíveis gerados pelos ecossistemas. Estes últimos, por sua vez, são os SEs. Essa diferenciação de conceitos é importante e deixa claro o caráter de externalidade positiva dos SAs: o agente que os provê produz benefícios que são apropriados coletivamente, já que a grande maioria dos SEs tem natureza de bens públicos.

2 Os casos internacionais são: (Vittel (França), Catskill-Delaware (EUA) e Pagos por Servicios Ambientales (Costa Rica). Os nacionais são: Conservador das Águas (município de Extrema-MG), Projeto Oásis (Região Metropolitana de São Paulo, SP, e município de Apucarana-PR), e o ProdutorES de Água, que posteriormente evoluiu para o Programa Reflorestar (Estado do Espírito Santo). O trabalho de referência é o de Simões (2014). Sugere-se também a consulta a Veiga e Gavaldão (2011) para as iniciativas brasileiras.

${ }^{3}$ Há, também, outras definições de PSA mais abrangentes, como a que fala que é um mecanismo que, na maioria das vezes, diz respeito a qualquer tipo de política para a conservação que seja baseada em mecanismos de mercado, incluindo emissão de ecocertificados, concessão de incentivos (como isenção fiscal), subsídios, etc (ANDRADE; FASIABEN, 2009)

${ }^{4}$ Serviços hidrológicos são todos os serviços ecossistêmicos ligados à oferta e qualidade da água.

${ }^{5}$ Em função do grande volume de informações sobre cada caso analisado, optou-se por apresentá-las em formato de quadros sintéticos. Decidiu-se, ainda, por posicionar tais quadros ao final do artigo de modo a não prejudicar a fluidez do texto principal. 
REVISITANDO A TEORIA E COMPREENDENDO A PRÁTICA: análise de casos de pagamento por serviços ambientais

\section{APÊNDICES}

APÊNDICE A - Características gerais dos casos internacionais de PSA analisados - parte 1

\begin{tabular}{|c|c|c|c|c|}
\hline Casos estudados & $\begin{array}{l}\text { Quem/quando } \\
\text { iniciou? }\end{array}$ & $\begin{array}{c}\text { Escala espacial e } \\
\text { tamanho atual }\end{array}$ & Intermediários & $\begin{array}{c}\text { Apoio de } \\
\text { doadores e } \\
\text { financiadores } \\
\text { externos }\end{array}$ \\
\hline $\begin{array}{l}\text { Vittel (Nestté } \\
\text { Waters), França }\end{array}$ & Vittel; em 1993 & $\begin{array}{l}\text { Bacia hidrográfica } \\
\text { da fonte; } 5.100 \text { ha. }\end{array}$ & $\begin{array}{l}\text { Agrivair (agência de extensão } \\
\text { rural criada pela Vittel). }\end{array}$ & Não. \\
\hline $\begin{array}{l}\text { Catskill-Delaware, } \\
\text { Nova York }\end{array}$ & $\begin{array}{l}\text { Prefeitura de } \\
\text { Nova York; em } \\
1997 .\end{array}$ & $\begin{array}{l}\text { Bacia hidrográfica; } \\
\text { desconhecido. }\end{array}$ & $\begin{array}{l}\text { Watershed Agricultural } \\
\text { Concil (agência criada pelos } \\
\text { proprietários rurais de Cat-Del). }\end{array}$ & $\begin{array}{l}\text { Govemo do } \\
\text { estado de Nova } \\
\text { York. }\end{array}$ \\
\hline $\begin{array}{l}\text { PPSA, Costa } \\
\text { Rica }\end{array}$ & $\begin{array}{l}\text { Governo federal; } \\
\text { em } 1997 .\end{array}$ & $\begin{array}{l}\text { Nacional, em } \\
\text { áreas prioritárias; } \\
\text { mais de 1.000.000 } \\
\text { ha (até 2012). } \\
\end{array}$ & $\begin{array}{l}\text { FONAFIFO, com apoio da } \\
\text { SINAC, ONGs, e engenheiros } \\
\text { florestais privados. }\end{array}$ & GEF e KfW. \\
\hline $\begin{array}{l}\text { Conservador das } \\
\text { Águas, Extrema } \\
\text { (MG) }\end{array}$ & $\begin{array}{l}\text { Prefeitura de } \\
\text { Extrema; em } \\
2005 .\end{array}$ & $\begin{array}{l}\text { Sub-bacias } \\
\text { hidrográficas das } \\
\text { Posses e do Salto; } \\
2.850 \text { ha (em } \\
\text { 2011). }\end{array}$ & $\begin{array}{l}\text { Prefeitura de Extrema, governo } \\
\text { do estado (IEF-MG), e um } \\
\text { conjunto de instituições do } \\
\text { terceiro setor. }\end{array}$ & $\begin{array}{l}\text { TNC, SOS Mata } \\
\text { Atântica, e } \\
\text { diversos outros. }\end{array}$ \\
\hline
\end{tabular}

Fonte: Elaborado pelos autores, com base na pesquisa.

APÊNDICE B - Características gerais dos casos internacionais de PSA analisados - parte 2

\begin{tabular}{|c|c|c|c|c|c|c|}
\hline $\begin{array}{c}\text { Casos } \\
\text { estudados }\end{array}$ & Objetivo geral & $\begin{array}{l}\text { SAs remu- } \\
\text { nerados }\end{array}$ & SEs enfocados & $\begin{array}{l}\text { Quem } \\
\text { "compra"? }\end{array}$ & $\begin{array}{c}\text { Quem } \\
\text { também } \\
\text { mais se } \\
\text { beneficia? }\end{array}$ & $\begin{array}{l}\text { Quem } \\
\text { "vende"? }\end{array}$ \\
\hline $\begin{array}{l}\text { Vittel } \\
\text { (Nestlé } \\
\text { Waters), } \\
\text { França }\end{array}$ & $\begin{array}{l}\text { Garantir a } \\
\text { qualidade da } \\
\text { água }\end{array}$ & $\begin{array}{l}\text { Melhores } \\
\text { práticas na } \\
\text { pecuária leiteira }\end{array}$ & $\begin{array}{l}\text { Qualidade da } \\
\text { água }\end{array}$ & $\begin{array}{l}\text { Vittel (Nestlé } \\
\text { Waters) }\end{array}$ & $\begin{array}{l}\text { Agentes } \\
\text { situados } \\
\text { rio abaixo } \\
\text { na bacia } \\
\text { hidrográfica }\end{array}$ & $\begin{array}{l}\text { Produtores } \\
\text { rurais da bacia } \\
\text { hidrográfica }\end{array}$ \\
\hline $\begin{array}{l}\text { Catskill- } \\
\text { Delaware, } \\
\text { Nova } \\
\text { York }\end{array}$ & $\begin{array}{l}\text { Garantir a } \\
\text { qualidade da } \\
\text { água. }\end{array}$ & $\begin{array}{l}\text { Melhores } \\
\text { práticas nas } \\
\text { atividades } \\
\text { agropecuárias, } \\
\text { saneamento } \\
\text { básico } \\
\text { adequado e } \\
\text { conservação } \\
\text { florestal. }\end{array}$ & $\begin{array}{l}\text { Qualidade da } \\
\text { água. }\end{array}$ & $\begin{array}{l}\text { Prefeitura de } \\
\text { Nova York. }\end{array}$ & $\begin{array}{l}\text { Usuários } \\
\text { de água; } \\
\text { indústria } \\
\text { do turismo; } \\
\text { economia } \\
\text { local }\end{array}$ & $\begin{array}{l}\text { Produtores } \\
\text { rurais da bacia } \\
\text { hidrográfica. }\end{array}$ \\
\hline $\begin{array}{l}\text { PPSA, } \\
\text { Costa Rica }\end{array}$ & $\begin{array}{l}\text { Evitar o } \\
\text { desmatamento } \\
\text { e promover o } \\
\text { reflorestamento. }\end{array}$ & $\begin{array}{l}\text { Conservação } \\
\text { florestal, } \\
\text { plantação } \\
\text { de florestas } \\
\text { e sistemas } \\
\text { agroflorestais. }\end{array}$ & $\begin{array}{l}\text { Qualidade e } \\
\text { quantidade } \\
\text { de água; } \\
\text { sequestro } \\
\text { de carbono; } \\
\text { biodiversidade; } \\
\text { beleza cênica. }\end{array}$ & $\begin{array}{l}\text { FONAFIFO } \\
\text { (agência } \\
\text { autônoma do } \\
\text { Estado). }\end{array}$ & $\begin{array}{l}\text { Indústria } \\
\text { do turismo; } \\
\text { usuários de } \\
\text { água. }\end{array}$ & $\begin{array}{l}\text { Proprietários } \\
\text { rurais da } \\
\text { áreas } \\
\text { prioritárias } \\
\text { (espalhadas } \\
\text { pelo território) }\end{array}$ \\
\hline
\end{tabular}

Fonte: Elaborado pelos autores, com base na pesquisa. 
Marcelo Silva Simões | Daniel Caixeta Andrade

APÊNDICE C - Características gerais dos casos nacionais de PSA analisados - parte 1

\begin{tabular}{|c|c|c|c|c|}
\hline $\begin{array}{c}\text { Casos } \\
\text { estudados }\end{array}$ & $\begin{array}{l}\text { Quem/quando } \\
\text { iniciou? }\end{array}$ & $\begin{array}{l}\text { Escala espacial e tamanho } \\
\text { atual }\end{array}$ & Intermediários & $\begin{array}{l}\text { Apoio de doadores } \\
\text { e financiadores } \\
\text { externos }\end{array}$ \\
\hline $\begin{array}{l}\text { Conservador } \\
\text { das Águas, } \\
\text { Extrema (MG) }\end{array}$ & $\begin{array}{l}\text { Prefeitura de } \\
\text { Extrema; em } \\
2005 .\end{array}$ & $\begin{array}{l}\text { Sub-bacias hidrográficas das } \\
\text { Posses e do Salto; } 2.850 \text { ha } \\
\text { (em 2011). }\end{array}$ & $\begin{array}{l}\text { Prefeitura de } \\
\text { Extrema, governo } \\
\text { do estado (IEF-MG), } \\
\text { e um conjunto } \\
\text { de instituições do } \\
\text { terceiro setor. }\end{array}$ & $\begin{array}{l}\text { TNC, SOS Mata } \\
\text { Atlântica, e diversos } \\
\text { outros. }\end{array}$ \\
\hline Oásis (RMSP) & FGB; 2006 & $\begin{array}{l}\text { Bacia hidrográfica de } \\
\text { Guarapiranga e Áreas } \\
\text { de Proteção Ambiental } \\
\text { municipais do Capiravi- } \\
\text { Monos; } 747,7 \text { ha e } 101 \\
\text { nascentes (em 2011). }\end{array}$ & $\begin{array}{l}\text { FGB e escritório } \\
\text { de advocacia } \\
\text { Losso, Tomasetti \& } \\
\text { Leonardo. }\end{array}$ & Não \\
\hline $\begin{array}{l}\text { Oásis } \\
\text { (Apucarana) }\end{array}$ & $\begin{array}{l}\text { Prefeitura de } \\
\text { Apucarana; } \\
2009\end{array}$ & $\begin{array}{l}\text { Bacias hidrográficas dos } \\
\text { Rios Pirapó, Tibagi e Ivaí, no } \\
\text { perimetro de Apucarana-PR. } \\
800 \text { ha e } 613 \text { nascentes } \\
\text { (em 2011). }\end{array}$ & SEMATUR. & ANA. \\
\hline $\begin{array}{l}\text { ProdutorES de } \\
\text { Água }\end{array}$ & IEMA; 2009 & $\begin{array}{l}\text { Bacias hidrográficas dos } \\
\text { Rios Benevente (Alfredo } \\
\text { Chaves), Guandu (Brejetuba } \\
\text { e Afonso Cláudio) e São José } \\
\text { (Mantenópolis e Alto Rio } \\
\text { Novo); 3.772,5 ha (em 2012). }\end{array}$ & $\begin{array}{l}\text { IEMA (executor do } \\
\text { PSA) e BANDES } \\
\text { (gestão do } \\
\text { FUNDÁGUA) }\end{array}$ & Não. \\
\hline Reflorestar & $\begin{array}{l}\text { SEAMAe } \\
\text { SEAG; } 2012 .\end{array}$ & $\begin{array}{l}\text { Todo o estado de Espirito } \\
\text { Santo. }\end{array}$ & $\begin{array}{l}\text { IEMA (executor do } \\
\text { PSA) e BANDES } \\
\text { (gestão do } \\
\text { FUNDÁGUA) }\end{array}$ & Desconhecido. \\
\hline
\end{tabular}

Fonte: Elaborado pelos autores, com base na pesquisa.

APÊNDICE D - Características gerais dos casos nacionais de PSA analisados - parte 2

\begin{tabular}{|l|l|l|l|l|l|l|}
\hline $\begin{array}{c}\text { Casos } \\
\text { estudados }\end{array}$ & Objetivo geral & $\begin{array}{c}\text { SAs } \\
\text { remunerados }\end{array}$ & $\begin{array}{c}\text { SEs } \\
\text { enfocados }\end{array}$ & $\begin{array}{c}\text { Quem } \\
\text { Quem } \\
\text { "compra"? }\end{array}$ & $\begin{array}{l}\text { também } \\
\text { mais se } \\
\text { beneficia? }\end{array}$ & $\begin{array}{l}\text { Quem } \\
\text { "vende"? }\end{array}$ \\
\hline $\begin{array}{l}\text { Conservador } \\
\text { das Águas, } \\
\text { Extrema } \\
\text { (MG) }\end{array}$ & $\begin{array}{l}\text { Regularização } \\
\text { ambiental e } \\
\text { garantia de } \\
\text { qualidade } \\
\text { e oferta de } \\
\text { água. }\end{array}$ & $\begin{array}{l}\text { Conservação } \\
\text { florestal e } \\
\text { reflorestamento } \\
\text { nas áreas de } \\
\text { mananciais, } \\
\text { práticas } \\
\text { mecânicas, } \\
\text { adequação da } \\
\text { estrutura viária } \\
\text { e saneamento } \\
\text { básico. }\end{array}$ & $\begin{array}{l}\text { Qualidade e } \\
\text { quantidade } \\
\text { de água; } \\
\text { proteção } \\
\text { contra } \\
\text { erosão do } \\
\text { solo. }\end{array}$ & $\begin{array}{l}\text { Prefeitura } \\
\text { de Extrema } \\
\text { (via } \\
\text { FMPSA); } \\
\text { Governo } \\
\text { de Minas } \\
\text { Gerais } \\
\text { (via IEF); } \\
\text { Comitês } \\
\text { PCJ. }\end{array}$ & $\begin{array}{l}\text { Economia } \\
\text { da cidade; } \\
\text { usuários } \\
\text { de água. }\end{array}$ & $\begin{array}{l}\text { Produtores ru- } \\
\text { rais das áreas } \\
\text { prionitárias. }\end{array}$ \\
\hline
\end{tabular}


REVISITANDO A TEORIA E COMPREENDENDO A PRÁTICA: análise de casos de pagamento por serviços ambientais

\begin{tabular}{|c|c|c|c|c|c|c|}
\hline $\begin{array}{l}\text { Oásis } \\
\text { (RMSP) }\end{array}$ & $\begin{array}{l}\text { Proteção de } \\
\text { mananciais } \\
\text { da RMSP }\end{array}$ & $\begin{array}{l}\text { Conservação } \\
\text { florestal nas } \\
\text { áreas de } \\
\text { mananciais. }\end{array}$ & $\begin{array}{l}\text { Armazena- } \\
\text { mento de } \\
\text { água; contro- } \\
\text { le de erosão; } \\
\text { qualidade da } \\
\text { água. }\end{array}$ & $\begin{array}{l}\text { Fundação } \\
\text { MCFAe } \\
\text { Instituto } \\
\text { CSHG. }\end{array}$ & $\begin{array}{l}\text { Popu- } \\
\text { lação e } \\
\text { empresas } \\
\text { intensivas } \\
\text { em água } \\
\text { downstre- } \\
\text { am. }\end{array}$ & $\begin{array}{l}\text { Proprietários } \\
\text { de terras com } \\
\text { características } \\
\text { preferencias } \\
\text { nas áreas } \\
\text { prioritárias. }\end{array}$ \\
\hline $\begin{array}{l}\text { Oásis (Apu- } \\
\text { carana) }\end{array}$ & $\begin{array}{l}\text { Preservar } \\
\text { e aumentar } \\
\text { a cobertura } \\
\text { florestal em } \\
\text { áreas de } \\
\text { mananciais. }\end{array}$ & $\begin{array}{l}\text { Conservação } \\
\text { florestal, } \\
\text { reflorestamento } \\
\text { nas áreas de } \\
\text { mananciais } \\
\text { e práticas } \\
\text { mecânicas } \\
\text { "amigáveis". }\end{array}$ & $\begin{array}{l}\text { Armazena- } \\
\text { mento de } \\
\text { água; contro- } \\
\text { le de erosão } \\
\text { do solo; } \\
\text { qualidade da } \\
\text { água. }\end{array}$ & $\begin{array}{l}\text { SANEPAR } \\
\text { (1\% de sua } \\
\text { arreca- } \\
\text { dação) } \\
\text { e ICMS- } \\
\text {-Ecológico } \\
\text { (empresa } \\
\text { local de } \\
\text { abaste- } \\
\text { cimento } \\
\text { público de } \\
\text { água); re- } \\
\text { cursos ge- } \\
\text { ridos pelo } \\
\text { FMMA. }\end{array}$ & $\begin{array}{l}\text { Popula- } \\
\text { ção da } \\
\text { região e } \\
\text { empresas } \\
\text { intensivas } \\
\text { em água } \\
\text { downs- } \\
\text { tream; } \\
\text { economia } \\
\text { local. }\end{array}$ & $\begin{array}{l}\text { Proprietários } \\
\text { rurais em áre- } \\
\text { as prioritárias. }\end{array}$ \\
\hline $\begin{array}{l}\text { Produtores } \\
\text { de Água }\end{array}$ & $\begin{array}{l}\text { Reduziro } \\
\text { processo de } \\
\text { erosão do } \\
\text { solo e o risco } \\
\text { de enchentes } \\
\text { downstream. }\end{array}$ & $\begin{array}{l}\text { Conservação } \\
\text { da floresta em } \\
\text { pé nas zonas } \\
\text { ripárias. }\end{array}$ & $\begin{array}{l}\text { Qualidade e } \\
\text { disponibilida- } \\
\text { de da água. }\end{array}$ & $\begin{array}{l}\text { FUN- } \\
\text { DÁGUA } \\
\text { (recursos } \\
\text { de royaties } \\
\text { do petróleo } \\
\text { e compen- } \\
\text { sações } \\
\text { pelo } \\
\text { uso dos } \\
\text { recursos } \\
\text { hídricos), } \\
\text { principal- } \\
\text { mente. }\end{array}$ & $\begin{array}{l}\text { Popu- } \\
\text { lação e } \\
\text { empresas } \\
\text { intensivas } \\
\text { em água } \\
\text { downstre- } \\
\text { am. }\end{array}$ & $\begin{array}{l}\text { Proprietários } \\
\text { rurais em } \\
\text { áreas ripárias. }\end{array}$ \\
\hline Reflorestar & $\begin{array}{l}\text { Manter, } \\
\text { recuperar } \\
\text { e ampliar a } \\
\text { cobertura } \\
\text { florestal, com } \\
\text { geração de } \\
\text { oportunidades } \\
\text { e renda para } \\
\text { o produtor } \\
\text { rural. }\end{array}$ & $\begin{array}{l}\text { Conservação } \\
\text { da floresta } \\
\text { em pé nas } \\
\text { zonas ripárias, } \\
\text { reflorestamento } \\
\text { e regeneração } \\
\text { natural, e } \\
\text { práticas de } \\
\text { uso da terra } \\
\text { "amigáveis". }\end{array}$ & $\begin{array}{l}\text { Mesmo do } \\
\text { ProdutorES } \\
\text { de Água }\end{array}$ & $\begin{array}{l}\text { Mesmo do } \\
\text { ProdutorES } \\
\text { de Água }\end{array}$ & $\begin{array}{l}\text { Mesmo do } \\
\text { Produto- } \\
\text { rES de } \\
\text { Água }\end{array}$ & $\begin{array}{l}\text { Qualquer } \\
\text { proprietários } \\
\text { rurais que se } \\
\text { cadastrarem. }\end{array}$ \\
\hline
\end{tabular}

Fonte: Elaborado pelos autores, com base na pesquisa. 
Marcelo Silva Simões | Daniel Caixeta Andrade

APÊNDICE E - Experiências de PSA confrontadas com a conceituação coaseana e motivos para maior ou menor distanciamento frente a este referencial

\begin{tabular}{|c|c|c|}
\hline 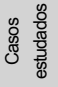 & $\begin{array}{l}\text { Grau de aderência da } \\
\text { experiência à conceituação } \\
\text { coaseana }\end{array}$ & Principais motivos para o distanciamento em relação ao "PSA coaseano" \\
\hline 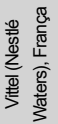 & Elevado & Elevados custos de transação; \\
\hline 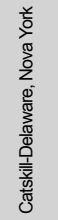 & Médio & $\begin{array}{l}\text { Elevado número de produtores rurais envolvidos; } \\
\text { Elevados custos de transação; } \\
\text { Necessidade de complementação com outros instrumentos para proteger a } \\
\text { geração de renda das populações rurais afetadas. Isso mostra que, o critério de } \\
\text { eficiência na prestação de SAs não é o único objetivo; } \\
\text { Financiamento do mecanismo com recursos públicos, por tributação direta dos } \\
\text { usuários finais dos recursos hídricos. }\end{array}$ \\
\hline 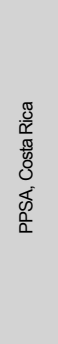 & Baixo & $\begin{array}{l}\text { Elevado número de produtores rurais envolvidos; } \\
\text { Elevados custos de transação; } \\
\text { Esquema de grande escala territorial; } \\
\text { Politica multiobjetivada (metas ambientais e socioeconômicas); } \\
\text { Baixa focalização na alocação dos recursos financeiros; } \\
\text { Prestação compulsória do SA de proteção contra o desmatamento de vegetação } \\
\text { nativa, sendo o PSA uma ferramenta de legilimação desta proibição; } \\
\text { Vinculação dos recursos financeiros que financiam o PSA com tributação sobre } \\
\text { o uso da água e consumo de combustivel fóssil toma indireta a participação no } \\
\text { mecanismo do lado da "demanda" de SAs; } \\
\text { Métodos de valoração econômica dos SAs não são claramante compativeis } \\
\text { com o real valor destes. }\end{array}$ \\
\hline 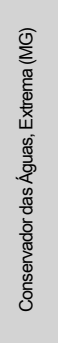 & Baixo & $\begin{array}{l}\text { Elevados custos de transação; } \\
\text { Criação do PSA como instrumento complementar para a adequação à } \\
\text { legislação ambiental; } \\
\text { Prestação compulsória do SA de proteção das áreas de mata ciliar nos } \\
\text { mananciais, sendo o PSA uma ferramenta de legitimação das regras do Código } \\
\text { Florestal e de apoio a adequação às mesmas; } \\
\text { Financiamento do PSAem maior parte por recursos do tesouro municipal, } \\
\text { tomando indireta a participação no mecanismo do lado da "demanda" de SAs; } \\
\text { Má compreensão das relações entre a prestação dos SAs e a oferta de SEs } \\
\text { hidrológicos por parte dos proprietários rurais; } \\
\text { Remuneração pela área total da propriedade, não proporcional àquelas em que } \\
\text { realmente se presta SAs. }\end{array}$ \\
\hline
\end{tabular}


REVISITANDO A TEORIA E COMPREENDENDO A PRÁTICA: análise de casos de pagamento por serviços ambientais

\begin{tabular}{|c|c|c|}
\hline 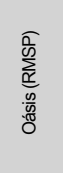 & Médio & $\begin{array}{l}\text { Elevado número de produtores rurais envolvidos; } \\
\text { Elevados custos de transação; } \\
\text { Financiamento não se dá pelos agentes mais demandantes de SAs } \\
\text { hidrológicos; } \\
\text { Frágil sustentabilidade financeira do mecanismo (visto ser doações as fontes } \\
\text { de recursos); }\end{array}$ \\
\hline 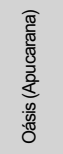 & Médio & $\begin{array}{l}\text { Elevado número de produtores rurais envolvidos; } \\
\text { Elevados custos de transação; } \\
\text { Criação do PSA como instrumento complementar para a adequação à } \\
\text { legislação ambiental; } \\
\text { Importante instrumento de complementação de renda das familias. }\end{array}$ \\
\hline 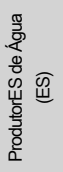 & Médio & $\begin{array}{l}\text { Elevado número de produtores rurais envolvidos; } \\
\text { Elevados custos de transação; } \\
\text { Baixa adicionalidade ambiental, visto o reconhecimento apenas dos SAs } \\
\text { prestados pela floresta que já era mantida "em pé". }\end{array}$ \\
\hline 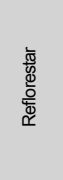 & Baixo - Médio & $\begin{array}{l}\text { Elevado número de produtores rurais envolvidos; } \\
\text { Elevados custos de transação; } \\
\text { Priorização de modalidades que geram SAs e renda agricola, ao invés de } \\
\text { alternativas que maximizam a geração dos primeiros; } \\
\text { Formatação como politica ambiental e agricola, complementar dentro de um } \\
\text { policymix que visa o desenvolvimento rural sustentável; }\end{array}$ \\
\hline
\end{tabular}

Fonte: Elaborado pelos autores, com base na pesquisa. 
